\title{
ROOT CAUSE ANALYSIS AND IMPACT OF WASTAGE ON PRODUCTION EFFECTIVENESS
}

\author{
Dr. SWETA RANI ${ }^{1}$, Dr. PURNIMA KUMARI ${ }^{2} \&$ SOUMOJEET PAUL $^{3}$ \\ ${ }^{1}$ Assistant Professor, Army Institute of Management, Kolkata \\ ${ }^{2}$ Assistant Professor, M.J.M. Mahila College, Katihar, Bihar \\ ${ }^{3 R}$ esearcher, Army Institute of Management, Kolkata
}

\begin{abstract}
The industries are the players of an economy, these players are engaged in economic activity and these economic activities help in income, growth and development of economy. The main player of these industries group is food industry. The food industries are engaged in conversion of agricultural product into consumer goods. The food industry is the industry that supplies most of the food to the population in the country. The food industry not only produces the food but also generate the wastages from the process of production phase. For the betterment of the economy and sustainable long term economy, these wastages need to be managed by the industries. The wastage can be controlled by recycling it.

KEYWORDS: Economy, Wastage, Population, Food Industry, Recycling, Controlled, Production, Agriculture \& Generating
\end{abstract}

Received: Feb 14, 202-; Accepted: Mar 04, 2020; Published: May 09, 2020; Paper Id.: IJBMRJUN20202

\section{INTRODUCTION}

The food industries are the primary sources for any country as these industries supply most of the food that is consumed by the people of the country. The food industry is the important industry for the country. Food refers to the process of converting primary material into finished products. In simple terms, we can say that, the process of the making a food involves converting agriculture product into the product, conducive for the buyers to consume. The industries are mostly busy in producing those products which are mostly consumed by the customer or which has highest number of demand in the market. After all, their motive is to earn maximum profit from their businesses. The food industry is the most successful industry. In the process of large production, food industries produce large number of waste. This is a big concern for any countries, as every country has limited number of resources which needs to be utilized wisely. Any such kind of wastages will be a serious concern for these countries. The food industry produces both types of wastage, that is, solids and liquids, which is generated from the process of production and consumption of food. This generated wastage becomes drastic when it affects the environment of the country by means of pollution. Further, it also affects the valuable biomass and nutrients. But this waste from food industry can be treated as boon for the country only if that waste is converted and utilized for feeding the people, those who can't afford a single time food. The food industry has to develop a separate regulatory agency which will help in utilization of the generated wastage from the processing of food. Food industries have to think about the future and the future generations, the future generation will suffer due to shortage of resources. The industries are responsible for the environmental degradation and any small initiative towards the safety of environment will be much appreciated. The food industry wastage can be controlled by implementing suitable policies and programmes. Today 
small contribution can help to lead a healthy environment. Food industry is the asset for the country. It needs to manage resources very carefully without producing wastages as any wastage can bring a huge loss to the economy.

\section{LITERATURE REVIEW}

Nicola JBeaumont, in his study title "Abatement cost curves: a viable management tool for enabling the achievement of winwin waste reduction strategies?". He assessed that the food industry wastage is creating environmental degradation by creating pollution in the environment. This pollution is responsible for various health hazards and slower economic growth and development. The industry is responsible for creating positive and negative effects. The positive effect of that industry is that they are responsible for economic growth of the country with the help of their well managed production and this leads to our GDP improvement in the country. The negative point is that wastage production by these industries will result in the depletion of healthy environment. Reducing industrial wastages can result in 'win-win', or at least 'win-draw', scenario for the industry and for the betterment of the country's economy. The industry can reduce the wastages by means of proper planning and effective management of wastages. With the effective implementation of waste reduction information system, management can help the industries in reducing cost and wastages. M.Osmani, in his study on 'Architects perspectives on construction waste reduction by design'. He assessed that there is a need to focus on the minimization of the construction waste and recycling of these waste. The recycling of the waste is nothing but recycling through effective management of waste resources. The recycling activities are needed to improve as these activities are attempted by only few industries. There is a need to implement a waste management department. The reduction of the wastage can be successful only if there is proper utilization of the wastages. Andreas A.Linningera, in his study on 'Planning of waste reduction strategies under uncertainty'. He assessed the Pharmaceutical Wastage. He assessed that the industry produces wastage throughout the production phase and it could be due to any reasons such as damage during transport or damage during storage or it could be of anything. This needs to be controlled by making proper planning for waste reduction. This will help in achieving the internal objective of the industry as well as helping the environmental directly and indirectly. The strategies for waste reduction can be like consumer education, innovative packaging and optimization of use of resources.

\section{RESEARCH FRAMEWORK}

\subsection{Research Design}

This research is quantitative in nature. It is conducted to find out the cost and wastage involved in production unit of Jubilant Foodwork. This research contains mostly secondary data. The research was conducted on the basis of data of 4 months (April-July). The secondary data was collected from Jubilant Foodwork Pvt ltd, Kolkata. Analysis and conclusion is derived with the help of these data. It has also been discussed with the production department for reducing the wastage during production.

\subsection{Research Methodology}

In order to find out the wastage cost, costing relating to dough has been conducted. Daily batch and wastage has been observed. Analysis has been done by using regression line, bar chart, line graph. After analysis, proper observation and recommendation have been drawn.

\subsection{Data Collection}

The data used in this project is secondary in nature. These are collected from Jubilant food work system. 
These are:

- Daily production unit

- Daily wastage in weight

- Ingredience price list

Monthly Production \& Wastage of Dough

Monthly Production

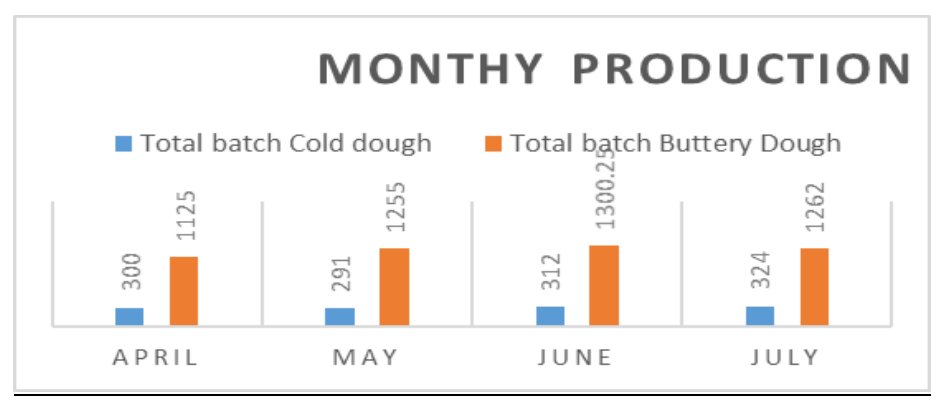

\begin{tabular}{|l|r|r|}
\hline Month & \multicolumn{3}{|c|}{ Total batch } \\
\hline & Cold dough & \multicolumn{3}{|c|}{ Buttery Dough } \\
\hline April & 300 & 1125 \\
\hline May & 291 & 1255 \\
\hline June & 312 & 1300.25 \\
\hline July & 324 & 1262 \\
\hline
\end{tabular}

Actual Weight vs Wastage Weight

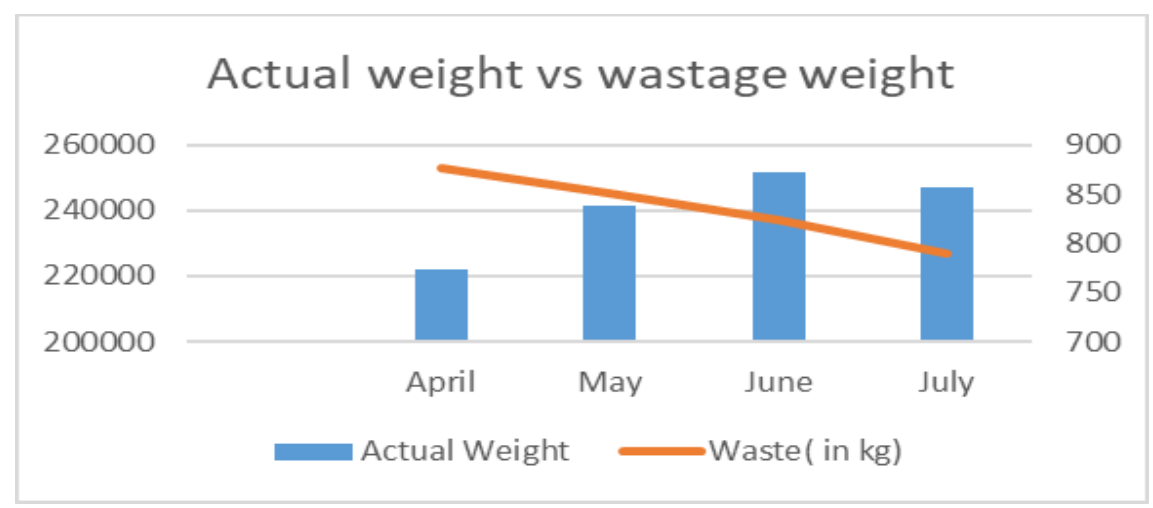




\begin{tabular}{|l|r|r|r|}
\hline Month & Actual Weight & Waste( in kg) & Net weight \\
\hline & & & \\
\hline April & 222072.18 & 876.01 & 221196.17 \\
\hline May & 241176.0116 & 850.98 & 240325.0316 \\
\hline June & 251449.8526 & 823.4 & 250626.4526 \\
\hline July & 247233.3856 & 789.92 & 246443.4656 \\
\hline
\end{tabular}

\section{Observation}

- There is a decrease in wastage weight throughout.

- Actual weight is increasing throughout the period, but in July, it is found to have a little bit decrease in weight.

- It is seen that as the wastage weight decreases, there is an increase in actual weight.

\section{Actual Cost vs Wastage Cost}

\begin{tabular}{|l|r|r|r|}
\hline Month & Actual cost & Wastage cost & Net cost \\
\hline & & & \\
\hline April & 8136566.467 & 32096.38232 & 8104470.085 \\
\hline May & 8856910.885 & 31251.25911 & 8825659.626 \\
\hline June & 9179481.042 & 30059.21305 & 9149421.829 \\
\hline July & 9048726.674 & 28911.02331 & 9019815.65 \\
\hline
\end{tabular}

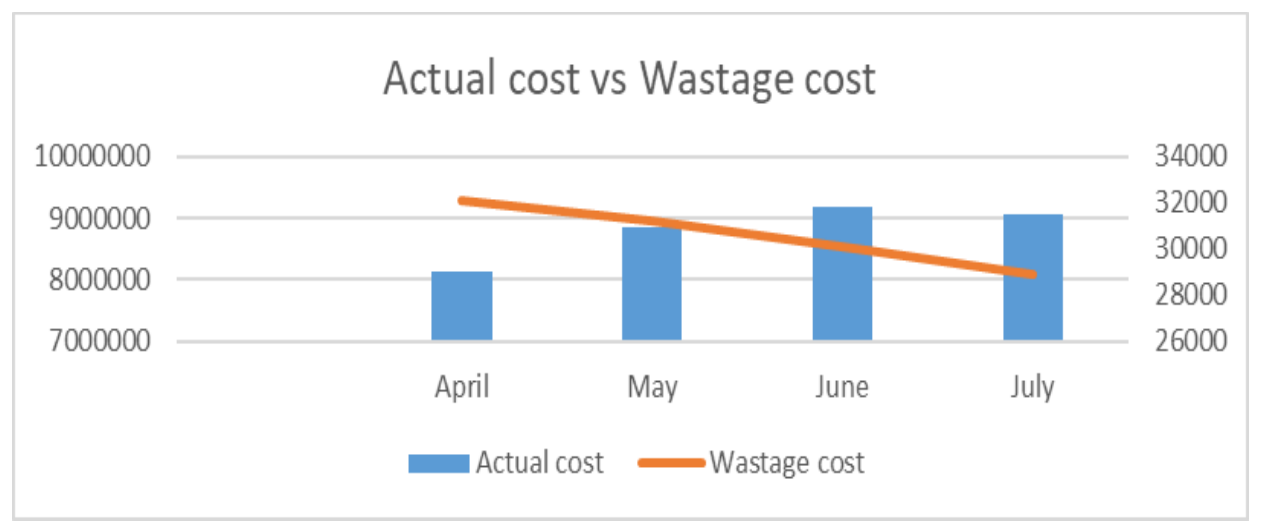

\section{Observation}

- Throughout the period, there is a decrease in wastage cost.

- Actual cost is increasing throughout the period, but in July, it is found to have little bit decrease in cost.

- It is seen that as the wastage cost decreases, there is an increase in actual cost. 


\begin{tabular}{|l|r|}
\hline Month & Cost \\
\hline April & 32096.38232 \\
\hline May & 31251.25911 \\
\hline June & 30059.21305 \\
\hline July & 28911.02331 \\
\hline
\end{tabular}

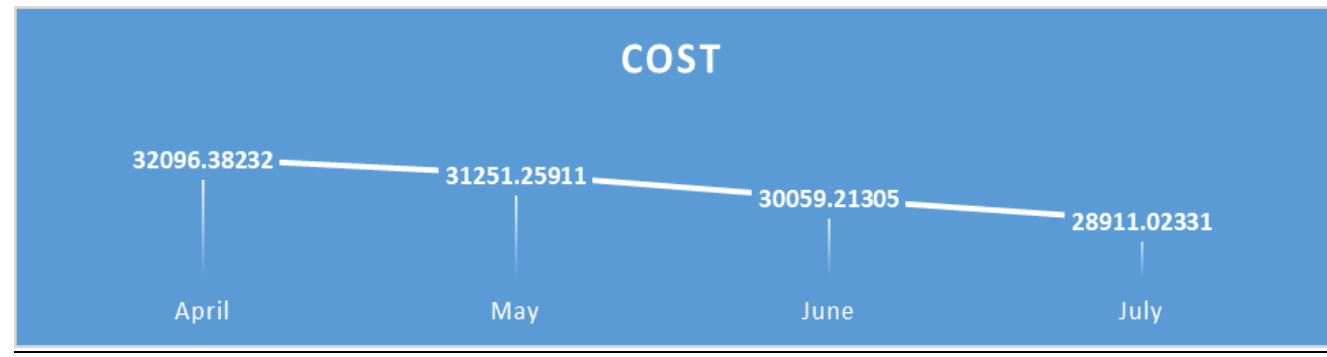

\section{Wastage Cost}

\section{Observation}

- Decreasing trend has been seen throughout the period.

- Wastage cost decreased from 32096.38 to 28911.02 .

\section{Wastage in Weight Vs No. of Batch}

\begin{tabular}{|l|r|r|}
\hline Month & Weight & No. of batch \\
\hline April & 876.01 & 1425 \\
\hline May & 850.98 & 1546 \\
\hline June & 823.4 & 1612.25 \\
\hline July & 789.92 & 1586 \\
\hline
\end{tabular}

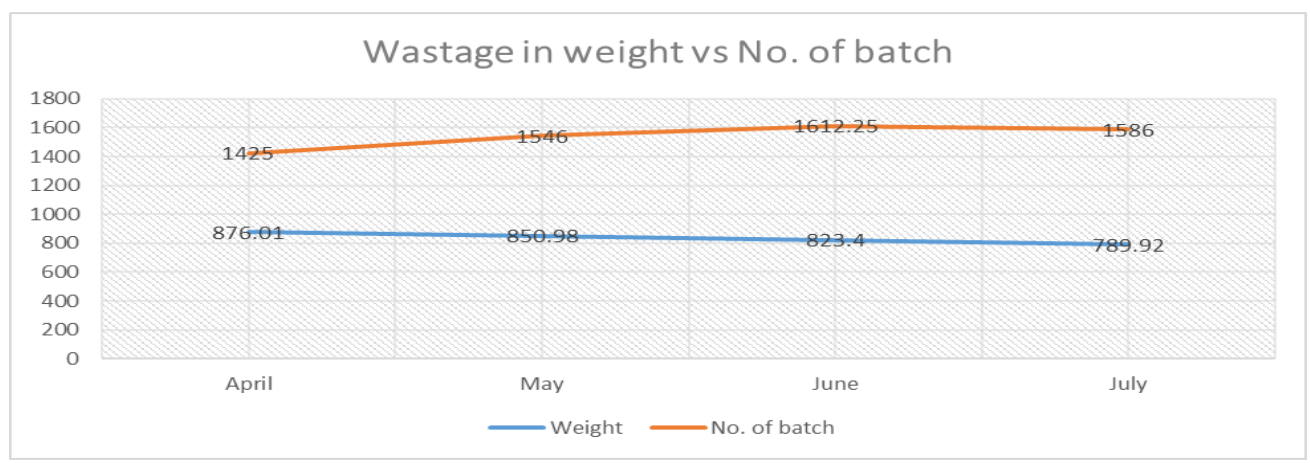

\section{Observation}

- There is a decrease in Wastage weight throughout the period.

- Number of batches increases throughout the period, but in July, there is little bit decrease in number of batches. 
- It is seen that as the wastage cost decreases, there is an increase in number of batches.

\section{FINDINGS}

Daily wastage cost of all the four months varied between Rs.1929.19 -Rs.632.19. Highest daily wastage cost was seen on $4^{\text {th }}$ June. Lowest daily wastage cost was seen on $29^{\text {th }} \mathrm{July}$. It was found that actual cost is within limit, but we see that wastage cost is decreasing at tentative level for three months, but in the month of July, there is an increase in wastage cost on the last week. It was also examined that Net cost (Actual cost - Wastage cost) of all the months varies between Rs.377634.35-Rs. 218935.57. Highest net cost was found on $4^{\text {th }}$ July. It was found that least net cost is found on $1^{\text {st }}$ April. Regression line of April, May \& June shows decreasing trend, but in July, there is an increasing trend which is under control. Daily wastage weight of all the four months varied between $53.42-16.7 \mathrm{~kg}$. Daily number of batches of all the four months varied between 68-37. Highest wastage weight was seen on $4^{\text {th }}$ June. Least wastage weight was seen on $5^{\text {th }}$ May. Highest number of batches were produced on $4^{\text {th }}$ July, highest and least number of batches were produced on $1^{\text {st }}$ April respectively. In all the four months, number of batches of buttery dough is higher than cold dough. Actual cost is increasing throughout, but in July, it is found to have a little bit decrease in cost. It is seen that as the wastage weight decreases, there is an increase in actual weight. Decreasing trend of wastage cost has been found throughout the four months. It was also observed that number of batches increases throughout the period, but in July, there is a little bit decrease in number of batches. It was seen that as the wastage cost decreases, there is an increase in number of batches.

\section{RECOMMENDATION}

The food industry should reduce the speed of convey belt in order to minimize the wastage. There must be proper hygiene by removing the tray which is not properly washed. The organisation should conduct weekly meeting regarding the status of the wastage. The organisation should maintain regular maintenance of wastage register so that there will be proper data about the wastage of food and according to that data, the organisation can formulate effective decision. The food industry needs to maintain weekly maintenance of the machine that is being used for production process. The ultimate aim of the food industry should be laying greater emphasis on cleaning and hygiene function so that there will be efficient functioning of food production with minimum wastage.

\section{REFERENCES}

1. Data collected from Jubliant Food Work Ltd and the data is provided by Mr. MukulMukherjee (Finance Department, Jubilant Food Work Ltd) are as following: Master day closing format Actual of Jubilant Food Work Ltd, Kolkata (April to July) and Data of daily wastage (April to July)

2. https://citoolkit.com/articles/waste-analysis/

3. https://www.jubilantfoodworks.com/about-us/company-profile

4. https://www.jubilantfoodworks.com/about-us/milestones

5. https://en.wikipedia.org/wiki/Jubilant_FoodWorks

6. Nicola J Beaumont "Abatement cost curves: a viable management tool for enabling the achievement of win-win waste reduction strategies?" Volume 71, July 2004, Pages 207-2015

7. Shailesh Tandon \& Akanssha Nigam, "Empirical Investigation on Mutual Funds and their Influence Due to International Economic Event”, International Journal of Business Management \& Research (IJBMR), Vol. 6, Issue 3, pp. 63 - 72 
8. Nai-Wen Chang \& Yuan-Ho Hsu, "Social Security Reforms in Aging Economy”, International Journal of Humanities and Social Sciences (IJHSS)", Vol. 6, Issue 3, pp.9-28

9. Jolly Masih, Amita Sharma, Ashish Sharma \& Jonathan Deutsch, "Demand Forecasting through Market Potential for Glutenfree Food Industry in India and USA", International Journal of Civil, Structural,Environmental and Infrastructure Engineering Research and Development (IJCSEIERD), Vol. 7, Issue 3, pp. 17-24

10. Mehul K. Shah, Chetan B. Bhatt \& Jaimin B. Dav, "NIR Spectroscopy: Technology Ready for Food Industries Applications", International Journal of Applied and Natural Sciences (IJANS), Vol. 5, Issue 1, pp. 129-138

11. Andreas A. Linningera "Planning of waste reduction strategies under uncertainty” Volume 24, 15 July 2000, Pages 1043-1048. M. Osmani "Architects perspectives on construction waste reduction by design" 

